\title{
Possibility of Sulfur Removal from Ladle Slag by Oxidation in the Temperature Range 1373-1673 K
}

\author{
Carl Allertz ${ }^{1} \cdot$ Du Sichen ${ }^{1}$
}

Published online: 5 May 2015

(C) The Minerals, Metals \& Materials Society (TMS) 2015

\begin{abstract}
Experiments were conducted to investigate the possibility of removing sulfur from used ladle slag by oxidation. Slag samples (solid, two-phase mixture, and liquid with a small fraction of solid $\mathrm{MgO}$ particles) were subjected to an oxygen-rich atmosphere in the temperature range $1373-1673 \mathrm{~K}$. The sulfur removal from the samples of solid and two-phase mixture was found to be a slow process due to the slow diffusion. The sulfur removal was found to have little dependence on temperature in the range $1373-1573 \mathrm{~K}$. When the slag was mostly liquid (at $1673 \mathrm{~K})$, the sulfur removal was significantly increased. More than $85 \%$ of the sulfur could be removed after 60 min of oxidation in pure oxygen. An increase in oxygen partial pressure was found to increase the desulfurization slightly. Increasing the $\mathrm{Al}_{2} \mathrm{O}_{3}$ content in the slag decreased the degree of sulfur removal.
\end{abstract}

Keywords Sulfur · Ladle slag · Desulfurization · Steelmaking

\section{Introduction}

One of the most important processes in producing high quality steel is the removal of sulfur. The final sulfur removal takes place in the ladle where a synthetic slag with high affinity to sulfur is used. Sulfur is then transferred from the steel to the slag. After the ladle treatment, the slag is discarded. For some

Du Sichen

sichen@kth.se

1 Department of Materials Science and Engineering, KTH Royal Institute of Technology, 10044 Stockholm, Sweden steel processes, the main impurity element in the slag after ladle treatment is sulfur. The high content of sulfur in the slag prohibits the slag for being reused in production and even recycling. The amount of synthetic slag used in typical ladle treatment operations for production of high quality steel is about $1-2 \%$ of the steel by weight. One can easily recognize the potential benefit if the slag could be reused in production instead of being discarded after use. This would not only be economically beneficial but also environmentally sound since the consumption of raw materials such as $\mathrm{CaO}, \mathrm{Al}_{2} \mathrm{O}_{3}$ can be greatly reduced. However, for slag to be reused in production, the sulfur concentration of the used slag needs to be greatly reduced.

It has been shown earlier that $\mathrm{CaS}$ can be oxidized into $\mathrm{CaO}$ at elevated temperatures $[1,2]$. The sulfur forms $\mathrm{SO}_{2}$ gas. One would expect that it would be possible to remove sulfur from used slag through an oxidation route. Earlier studies on liquid blast furnace slags reported that sulfur could escape from the slag in the form of $\mathrm{S}_{2}, \mathrm{SO}_{2}$, or as $\mathrm{H}_{2} \mathrm{~S}$ $[3,4]$. Recently, it was reported that sulfur could efficiently be removed from solid ladle slag containing $\mathrm{CaF}_{2}$ by reaction with $\mathrm{Ar}-\mathrm{O}_{2}$ mixture at temperatures above $1273 \mathrm{~K}$ [5]. It would be interesting to investigate this further in the case of ladle slag without $\mathrm{CaF}_{2}$. The aim of the present work was to investigate the possibility to remove sulfur from used ladle slag by oxidation at different temperatures.

\section{Experimental}

The experiments were carried out to oxidize sulfur at elevated temperatures. The temperature range for the experiments was $1373-1673 \mathrm{~K}$. An open circuit principle was utilized where fresh gas is continuously supplied into the reaction chamber, and any gaseous reaction products are 
transported away with the off gas. In most of the experiments, oxygen gas was employed. Nitrogen gas was used for lowering the oxygen partial pressure in some experiments.

\section{Materials}

The slag used in the present study was supplied by OVAKO Hofors. A large amount of slag (approximately $2 \mathrm{~kg}$ ) was collected subsequent to the vacuum degassing, when desulfurization of the steel already had been made. The slag was taken at one sampling occasion, in order to obtain similar starting slag composition for all experiments. The used ladle slag composition is given in Table 1. The slag was crushed into powders in two different size ranges, viz. big particles $1-3 \mathrm{~mm}$ in size and small particles $180-250 \mu \mathrm{m}$ in size. Reagent grade $\mathrm{Al}_{2} \mathrm{O}_{3}$ powder was used for adjusting the slag composition. The $\mathrm{Al}_{2} \mathrm{O}_{3}$ powder was calcinated at $1273 \mathrm{~K}$ for at least $5 \mathrm{~h}$ before the sample preparation. Three crucibles were used in the study, and they are listed in Table 2. Gases used in this study were pure argon, oxygen, and nitrogen (with the purity level 99.999, 99.5, $99.999 \%$, respectively, supplied by AGA).

\section{Experimental Setup}

The experimental setup is depicted in Fig. 1. The setup consisted of a resistance furnace with a vertical alumina reaction tube. The reaction tube is directly connected to a water cooled quenching chamber on its top. The alumina tube and the cooling chamber were completely sealed against the surroundings by O-rings. The furnace temperature was controlled by a Eurotherm controller using a thermocouple of type B (6\% Rh-30\% Rh). The even temperature hot zone $( \pm 2 \mathrm{~K})$ of the furnace was $5 \mathrm{~cm}$. For precise control of the sample temperature, an internal thermocouple type B (6\% Rh-30\% Rh) with an alumina

Table 1 Chemical composition of industrial slag

\begin{tabular}{lllll}
\hline \multicolumn{2}{l}{ Slag compostion (mass\%) } \\
\hline $\mathrm{Al}_{2} \mathrm{O}_{3}$ & $\mathrm{CaO}$ & $\mathrm{MgO}$ & $\mathrm{SiO}_{2}$ & $\mathrm{~S}$ \\
\hline 29.3 & 54.0 & 7.3 & 6.9 & 2.5 \\
\hline
\end{tabular}

Table 2 Crucibles used in the study

\begin{tabular}{lll}
\hline Material & Inner diameter $(\mathrm{mm})$ & Inner height $(\mathrm{mm})$ \\
\hline $\mathrm{Al}_{2} \mathrm{O}_{3}$ & 25 & 14 \\
$\mathrm{Al}_{2} \mathrm{O}_{3}$ & 20 & 14 \\
$\mathrm{MgO}$ & 20 & 14 \\
\hline
\end{tabular}

protection sheath was positioned just below the sample as can be seen in Fig. 1.

The sample was introduced into the hot zone and kept there by the holding crucible which was held by the pushrod via platinum wires. In order to ease the gas flow around the sample, 24 holes (diameter $3 \mathrm{~mm}$ ) were drilled out in the lower part of the crucible. This design is illustrated in the inset part of Fig. 1.

The gas inlet was located on the top of the furnace and the outlet on the bottom. The gas flow of each gas was controlled by a Bronkhorst flow meter $( \pm 0.5 \%)$.

\section{Experimental Procedure}

The slag sample was put into either an $\mathrm{Al}_{2} \mathrm{O}_{3}$ crucible or an $\mathrm{MgO}$ crucible. In the case of $\mathrm{Al}_{2} \mathrm{O}_{3}$ crucible, $9.5 \mathrm{~g}$ of slag

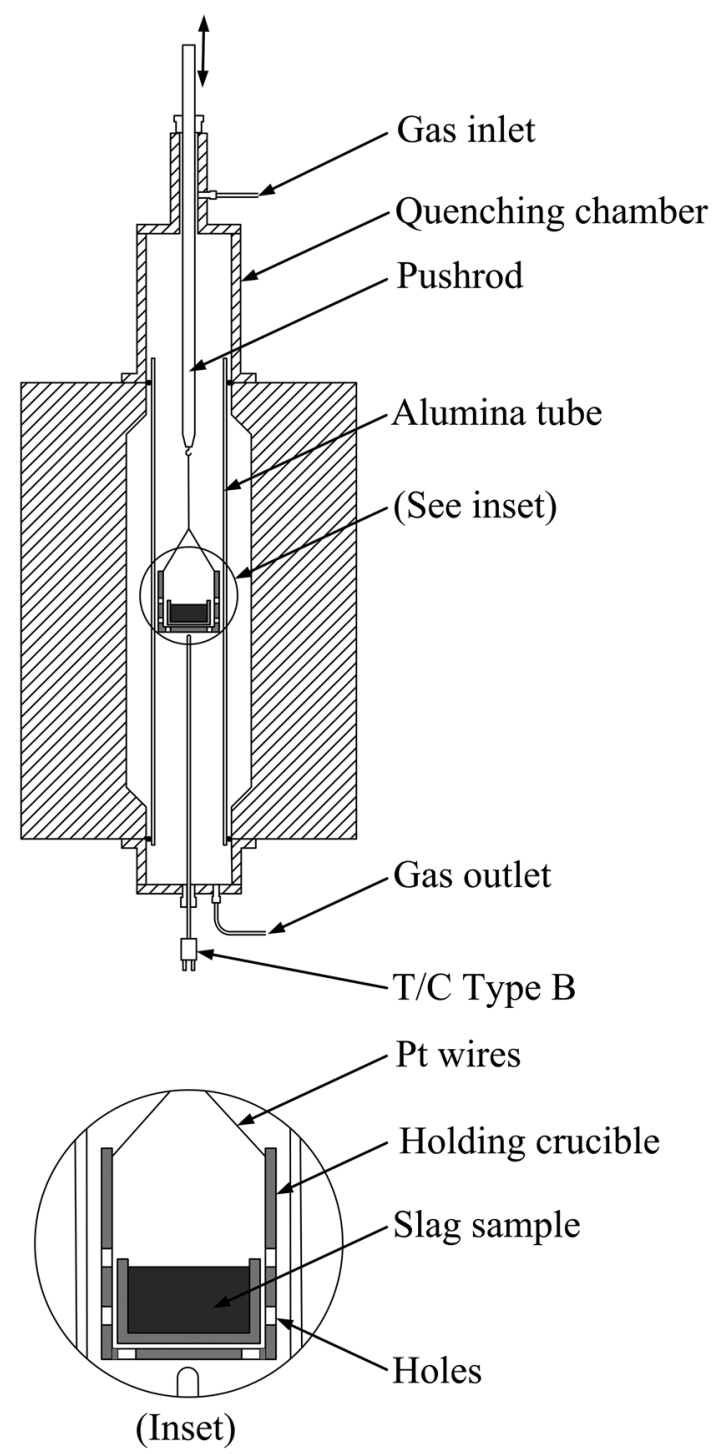

Fig. 1 Schematic of experimental apparatus 
was used, while in the case of $\mathrm{MgO}$ crucible, $6.5 \mathrm{~g}$ slag was used. In the experiments, where liquid phase was the major phase $(1673 \mathrm{~K})$, a mixture of the larger and smaller particles of slag was used. For the samples in solid state (1373, $1473 \mathrm{~K})$ or having two-phase mixture $(1573 \mathrm{~K})$, experiments were conducted separately using either particles of 1-3 mm in size or 180-250 $\mu \mathrm{m}$ in size. Some slags were mixed with $\mathrm{Al}_{2} \mathrm{O}_{3}$ powder prior being put into the crucible. In a typical run, the sample was placed in the holding crucible and positioned in the cooling chamber of the furnace. The furnace was completely sealed and evacuated for $30 \mathrm{~min}$. The furnace was back-filled with $\mathrm{Ar}$ gas and was heated up with a ramp speed of $2 \mathrm{~K} \mathrm{~min}^{-1}$. During heating, a constant argon flow of $0.05 \mathrm{~L} \mathrm{~min}^{-1}$ was kept. Upon reaching the target temperature, the sample was slowly lowered to the hot zone of the furnace to avoid thermal shock of the reaction tube. This procedure took approximately $15 \mathrm{~min}$. The sample was thereafter held in the hot zone for 15 min before switching the argon gas to the reaction gas. To examine the effect of holding time on the experiment, a longer holding time $(120 \mathrm{~min})$ was used. The reaction gas consisted of pure $\mathrm{O}_{2}$ or $\mathrm{O}_{2}-\mathrm{N}_{2}$ mixture with a total gas flow rate of $0.6-0.8 \mathrm{~L} \mathrm{~min}^{-1}$. After oxidation of a predetermined time, the sample was quickly lifted to the quenching chamber. Immediately, the reaction gas was switched to pure Ar at a high gas flow, $0.7 \mathrm{~L} \mathrm{~min}^{-1}$, in order to rapidly quench the sample. The sample was taken out of the cooling chamber. The reacted sample was carefully removed from the crucible and sent for analysis.

\section{Chemical Analysis}

All slag samples were analyzed for their final slag composition with X-ray Fluorescence, where the relative uncertainty is about $\pm 5 \%$. The final sulfur contents were analyzed with the LECO combustion technique. The relative uncertainty for this analysis was $\pm 5 \%$. Some slag samples were additionally analyzed using scanning electronic microscope SEM equipped with EDS. The microscopic study would provide the information regarding the phases present in the sample and the relative sulfur distribution between the phases.

\section{Results}

The experiments were carried out in the temperature range of 1373-1673 K. Pure $\mathrm{O}_{2}$ and $\mathrm{O}_{2}-\mathrm{N}_{2}$ mixtures were employed. Different flow rates of the reaction gas were used, varying in the range $0.6-0.8 \mathrm{~L} \mathrm{~min}^{-1}$. The initial sulfur content of the slag was 2.5 mass\%. The experimental conditions are summarized in Table 3 . The final analyzed slag compositions are given in Table 4.
Figure 2a-e presents the SEM microphotographs of the samples without oxidation, oxidized at 1373, 1473, 1573, and $1673 \mathrm{~K}$, respectively. The sample oxidized at 1373 and $1473 \mathrm{~K}$ has similar morphology as the slag sample without oxidation. Many phases are found in the slag without oxidation and at 1373 and $1473 \mathrm{~K}$ (Fig. 2a-c). Since the initial slag has been cooled down to room temperature from about $1873 \mathrm{~K}$, many solid phases precipitated during the cooling. These phases are also kept in the sample oxidized at $1473 \mathrm{~K}$, since this temperature is too low for the sample to reach thermodynamic equilibrium. In view of the fact that the phases in the unreacted sample depend very much on the cooling history, no attempt was made to identify all the phases in the sample. On the other hand, Fig. $2 d$ shows clearly the formation of a liquid phase (marked as phase 1) at $1573 \mathrm{~K}$. In addition, three other phases are identified in the sample oxidized at this temperature. These phases were identified to be $3 \mathrm{CaO} \cdot \mathrm{Al}_{2} \mathrm{O}_{3}$ (phase 2), $\mathrm{CaO} \cdot \mathrm{SiO}_{2}$ (phase 3 ), and $\mathrm{MgO}$ (phase 4). In view of the uncertainties related to EDS/SEM analysis and the fact that an industrial sample was used, this information should be used with caution. In the sample oxidized at $1673 \mathrm{~K}$, the majority of the slag is liquid, while a small fraction of solid $\mathrm{MgO}$ particles are also present.

In order to examine the sulfur distributions in the samples, Fig. 3a-d presents the sulfur mappings of the different samples. Due to the low remaining sulfur content at $1673 \mathrm{~K}$, the sulfur mapping at this temperature is not included. Figure $3 \mathrm{a}$ shows evidently the presence of CaS. It is well known that $\mathrm{CaS}$ cannot be formed during ladle treatment. The $\mathrm{CaS}$ is expected to be formed by precipitation during the cooling. In accordance with Fig. 2, the sulfur mappings in the samples oxidized at 1373 and $1473 \mathrm{~K}$ (Fig. 3b, c) are very similar as the one without oxidation. In Fig. 3d, no CaS particles can be found; instead, the sulfur is evenly distributed within the liquid phase.

To describe the sulfur removal, the degree of sulfur removal, $R_{S}$, defined in Eq. (1) is employed throughout this paper:

$R_{S}=\frac{(\operatorname{mass} \% S)_{\text {initial }}-(\operatorname{mass} \% S)_{\text {final }}}{(\operatorname{mass} \% S)_{\text {initial }}} \times 100$

The experimentally obtained $R_{S}$ is also included in Table 3.

\section{Discussion}

Firstly, it should be pointed out that an industrial slag was used for all measurements with an initial sulfur content of 2.5 mass\%. It is likely that the slag is not completely homogeneous in composition. The data presented in Table 3 
Table 3 Summary of experimental conditions and calculated degree of sulfur removal

\begin{tabular}{|c|c|c|c|c|c|c|c|c|}
\hline Sample & Crucible material & Particle size $(\mathrm{mm})$ & Addition $^{\mathrm{a}}$ & Temperature (K) & Reaction time (min) & $\mathrm{O}_{2}(\mathrm{~atm})$ & Gas flow (1/min) & $R_{S}$ \\
\hline S-1 & $\mathrm{Al}_{2} \mathrm{O}_{3}$ & $1-3$ & - & 1373 & 60 & 1 & 0.6 & 28 \\
\hline$S-2$ & $\mathrm{Al}_{2} \mathrm{O}_{3}$ & $1-3$ & - & 1473 & 60 & 1 & 0.6 & 30 \\
\hline$S-3$ & $\mathrm{Al}_{2} \mathrm{O}_{3}$ & $0.18-0.25$ & - & 1473 & 60 & 1 & 0.6 & 30 \\
\hline$S-4$ & $\mathrm{MgO}$ & $0.18-0.25$ & - & 1473 & 60 & 1 & 0.8 & 26 \\
\hline S-5 & $\mathrm{Al}_{2} \mathrm{O}_{3}$ & $1-3$ & - & 1573 & 60 & 1 & 0.6 & 34 \\
\hline S-6 & $\mathrm{Al}_{2} \mathrm{O}_{3}$ & Mix & - & 1673 & 60 & $0.05^{\mathrm{b}}$ & 0.6 & 73 \\
\hline S-7 & $\mathrm{Al}_{2} \mathrm{O}_{3}$ & Mix & - & 1673 & 60 & $0.21^{\mathrm{b}}$ & 0.6 & 68 \\
\hline$S-8$ & $\mathrm{Al}_{2} \mathrm{O}_{3}$ & $\operatorname{Mix}$ & - & 1673 & 60 & 1 & 0.6 & 89 \\
\hline S-9 & $\mathrm{Al}_{2} \mathrm{O}_{3}$ & Mix & - & 1673 & 60 & 1 & 0.6 & 87 \\
\hline S-10 & $\mathrm{Al}_{2} \mathrm{O}_{3}$ & Mix & - & 1673 & 30 & 1 & 0.6 & 78 \\
\hline S-11 & $\mathrm{Al}_{2} \mathrm{O}_{3}^{\mathrm{c}}$ & Mix & - & 1673 & 60 & 1 & 0.6 & 73 \\
\hline S-12 & $\mathrm{MgO}$ & Mix & - & 1673 & 60 & 1 & 0.6 & 70 \\
\hline S-13 & $\mathrm{MgO}$ & Mix & - & 1673 & 60 & 1 & 0.8 & 72 \\
\hline S-14 & $\mathrm{MgO}$ & Mix & - & 1673 & 30 & 1 & 0.6 & 46 \\
\hline S-15 & $\mathrm{MgO}$ & Mix & - & 1673 & 120 & 1 & 0.6 & 78 \\
\hline S-16 & $\mathrm{MgO}$ & Mix & - & 1673 & 60 & 1 & 0.6 & 67 \\
\hline S-17 & $\mathrm{MgO}$ & $0.18-0.25$ & $35 \% \mathrm{Al}_{2} \mathrm{O}_{3}$ & 1673 & 60 & 1 & 0.6 & 74 \\
\hline S-18 & $\mathrm{MgO}$ & $0.18-0.25$ & $40 \% \mathrm{Al}_{2} \mathrm{O}_{3}$ & 1673 & $60^{\mathrm{d}}$ & 1 & 0.6 & 57 \\
\hline S-19 & $\mathrm{Al}_{2} \mathrm{O}_{3}$ & $0.18-0.25$ & $40 \% \mathrm{Al}_{2} \mathrm{O}_{3}$ & 1673 & 60 & 1 & 0.6 & 31 \\
\hline S-20 & $\mathrm{MgO}$ & $0.18-0.25$ & $45 \% \mathrm{Al}_{2} \mathrm{O}_{3}$ & 1673 & 60 & 1 & 0.6 & 48 \\
\hline
\end{tabular}

${ }^{a}$ The additions given are the calculated total $\mathrm{Al}_{2} \mathrm{O}_{3}$ contents of the slag subsequent to melting

b The oxygen gas was balanced with $\mathrm{N}_{2}$ gas to $1 \mathrm{~atm}$

c This crucible had an inner diameter of $20 \mathrm{~mm}$

${ }^{\mathrm{d}}$ This sample had a prolonged heating time of $120 \mathrm{~min}$

could be associated with some uncertainties. Nevertheless, this uncertainty would not affect the present discussion. Some of the experimental conditions were repeated with several samples in order to check the reproducibility of the measurements, e.g., samples S-8, S-9 and samples S-12, S-16. The final results correspond well between the samples, indicating thereby satisfactory reproducibility of the current measurements.

The degree of sulfur removal is plotted as a function of temperature in Fig. 4. It is clearly seen that an increase of temperature has no appreciable effect on the sulfur removal between 1373 and $1573 \mathrm{~K}$. However, by increasing the temperature to $1673 \mathrm{~K}$, the sulfur removal is significantly increased. The substantial increase of sulfur removal at $1673 \mathrm{~K}$ is because the slag is mostly liquid at this temperature, as evidently seen in Fig. 2 e. The small fraction of solid $\mathrm{MgO}$ particles in the liquid slag also corresponds well with information about the quaternary $\mathrm{Al}_{2} \mathrm{O}_{3}-\mathrm{CaO}-\mathrm{MgO}-$ $\mathrm{SiO}_{2}$ system found in literature [6]. As shown in Fig. 2, the slag is completely solid below $1473 \mathrm{~K}$, forms a two-phase mixture at $1573 \mathrm{~K}$, and is mostly liquid at $1673 \mathrm{~K}$. Note that the fraction of liquid phase in the sample oxidized at
$1573 \mathrm{~K}$ is quite limited (see Fig. 2d). It is well known that gas-liquid reactions are faster than gas-solid reactions in general. This would explain the large difference in the removal of sulfur when the temperature is increased form 1573 to $1673 \mathrm{~K}$. Also the reaction mechanisms for solid, respectively, liquid slag could be very different.

The aim of the present study was to investigate the possibility and feasibility of removing sulfur from industrial ladle slag by oxidation. Since it is evidently shown that the sulfur removal is more efficient for liquid slag (Fig. 4), the main focus is therefore given to liquid slag.

\section{Thermodynamic Consideration}

In solid slag, sulfur can be removed by oxidation according to the following reaction:

$\mathrm{CaS}(s)+\frac{3}{2} \mathrm{O}_{2}(g)=\mathrm{CaO}(s)+\mathrm{SO}_{2}(g)$

As shown in the element mapping in Fig. 3a, CaS does exist in the industrial sample. The CaS phase is even stable in the sample studied up to $1473 \mathrm{~K}$. Sulfur also has the 
Table 4 Final chemical composition of the slag samples

\begin{tabular}{|c|c|c|c|c|c|}
\hline \multirow[t]{2}{*}{ Sample } & \multicolumn{5}{|c|}{ Final slag composition (mass\%) } \\
\hline & $\mathrm{Al}_{2} \mathrm{O}_{3}$ & $\mathrm{CaO}$ & $\mathrm{MgO}$ & $\mathrm{SiO}_{2}$ & $S$ \\
\hline S-1 & 29.8 & 54.2 & 7.4 & 6.8 & 1.81 \\
\hline S-2 & 29.7 & 54.1 & 7.6 & 6.9 & 1.76 \\
\hline S-3 & 29.8 & 54.1 & 7.5 & 6.8 & 1.75 \\
\hline S-4 & 29.7 & 53.9 & 7.6 & 6.9 & 1.85 \\
\hline S-5 & 30.0 & 53.9 & 7.6 & 6.8 & 1.66 \\
\hline S-6 & 41.5 & 45.5 & 6.4 & 5.9 & 0.68 \\
\hline S-7 & 40.6 & 46.2 & 6.3 & 6.1 & 0.80 \\
\hline S-8 & 44.2 & 43.5 & 6.2 & 5.8 & 0.27 \\
\hline S-9 & 42.6 & 44.8 & 6.4 & 5.9 & 0.33 \\
\hline S-10 & 41.0 & 45.8 & 6.6 & 6.0 & 0.56 \\
\hline S-11 & 47.3 & 39.6 & 6.8 & 5.6 & 0.67 \\
\hline S-12 & 30.4 & 53.9 & 7.6 & 7.2 & 0.76 \\
\hline S-13 & 30.0 & 54.3 & 8.0 & 6.9 & 0.71 \\
\hline S-14 & 30.0 & 54.1 & 7.6 & 6.9 & 1.34 \\
\hline S-15 & 30.1 & 54.1 & 8.3 & 6.9 & 0.54 \\
\hline S-16 & 33.9 & 48.3 & 6.9 & 7.1 & 0.83 \\
\hline S-17 & 35.0 & 49.8 & 7.1 & 7.3 & 0.65 \\
\hline S-18 & 40.9 & 44.7 & 6.8 & 6.6 & 1.07 \\
\hline S-19 & 46.1 & 38.7 & 7.7 & 5.7 & 1.73 \\
\hline S-20 & 44.8 & 41.7 & 6.8 & 5.5 & 1.29 \\
\hline
\end{tabular}

possibility to combine together with oxygen forming $\mathrm{CaSO}_{4}$. In such case, it would be very difficult to remove sulfur by further oxidation. The reaction where $\mathrm{CaS}$ reacts with oxygen and form $\mathrm{CaSO}_{4}$ is given in reaction (3):

$\mathrm{CaS}(s)+2 \mathrm{O}_{2}(g)=\mathrm{CaSO}_{4}(s)$

As can be seen from reactions (2) and (3), the reaction products will be determined by both the sulfur and oxygen potentials in the system. It would be useful to make a thermodynamic evaluation to examine the suitable conditions for removing sulfur from solid slag. A stability diagram of the $\mathrm{Ca}-\mathrm{S}-\mathrm{O}$ system is constructed for 1473 and $1638 \mathrm{~K}$ based on available thermodynamic data as listed in Table 5. This diagram is presented in Fig. 5. In the construction of the diagram, the activities for all condensed phases were set as unity. The potentials of oxygen and sulfur were chosen to be expressed as the partial pressures of oxygen and $\mathrm{SO}_{2}$, respectively. It should be pointed out that in reality the activities of the species $\mathrm{CaO}, \mathrm{CaS}$, and $\mathrm{CaSO}_{4}$, present in the slag would not be equal to unity. Nevertheless, the diagram can still be used for a qualitative indication about the suitable conditions for the removal of sulfur.

In order to remove sulfur from the slag by oxidation, the reaction product has to be $\mathrm{CaO}$ and $\mathrm{SO}_{2}$ gas $\left(\mathrm{CaSO}_{4}\right.$ would remain in the slag). In the diagram, it can be seen that at high oxygen pressures, e.g., unity, the pressure of $\mathrm{SO}_{2}$ needs to be maintained low in order to avoid the formation of sulfate. If the oxygen partial pressure is decreased, the pressure of $\mathrm{SO}_{2}$ can be increased while still avoiding the formation of sulfate. At low oxygen partial pressure, e.g., $10^{-6}$ atm (at $1638 \mathrm{~K}$ ), the $\mathrm{SO}_{2}$ pressure can even be above unity, while $\mathrm{CaO}$ would remain as the reaction product. Based on this information, it would be reasonable to expect that a partial pressure of oxygen less than unity would be more suitable for the removal of sulfur by oxidation. However, one should also consider the mass balance with respect to oxygen for the sulfur removal. If a lower oxygen partial pressure is used, a larger volume of gas has to be used in order to supply the same amount of oxygen to the slag surface. This can be compensated to some extent by increasing the gas flow rate. However, at very low oxygen partial pressures, e.g., $10^{-6}$, this would be practically impossible. Fortunately, a high gas flow rate would constantly remove the $\mathrm{SO}_{2}$ gas produced and keep reaction (2) proceeding to the right-hand side. Figure 5 also indicates that increasing the temperature would help the sulfur removal.

\section{Sulfur Removal of Solid Slag}

The trend seen in Fig. 4 between 1373 and $1573 \mathrm{~K}$ suggests that the sulfur removal of slag depends very little on temperature when the sample is mostly solid. The independence of $R_{S}$ on temperature in the solid case suggests strongly that the reaction is controlled by diffusion through the solid particles. This argument is evidently supported by the sulfur mappings as shown in Fig. 3. In the industrial slag, $\mathrm{CaS}$ grains are found throughout the sample (Fig. 3a). After oxidation on the other hand (Fig. 3b, c), in the region close to the surface of the sample, $\mathrm{CaS}$ has vanished. In the central part of the sample, however, the sulfide phase is still evenly distributed. Figure $2 \mathrm{~d}$ indicates that a small amount of liquid phase has been formed at $1573 \mathrm{~K}$. The sulfide has been dissolved into the liquid phase, since no pure $\mathrm{CaS}$ phase can be found in this sample. However, the results shown in Fig. 4 indicate that the presence of the liquid phase has little effect on the sulfur removal. This is expected, since the small amount of liquid would not affect the diffusion of either sulfur or oxygen substantially. A comparison of $R_{S}$ between sample S-2 and S-3 in Table 3 indicates that there is no appreciable effect of particle size on the sulfur removal for the two particle sizes. It is worthwhile to point out that the gas flow rate of oxygen also has negligible effect of sulfur removal, as revealed by the comparison of $R_{S}$ between sample S-2 and sample S-4. These comparisons further support the present reasoning that the diffusion process through the particles is the rate controlling step in the case of solid samples. 
Fig. 2 SEM microphotographs of slag a without oxidation, b oxidation at $1373 \mathrm{~K}$, c oxidation at $1473 \mathrm{~K}$, d oxidation at $1573 \mathrm{~K}$, and e oxidation at $1673 \mathrm{~K}$

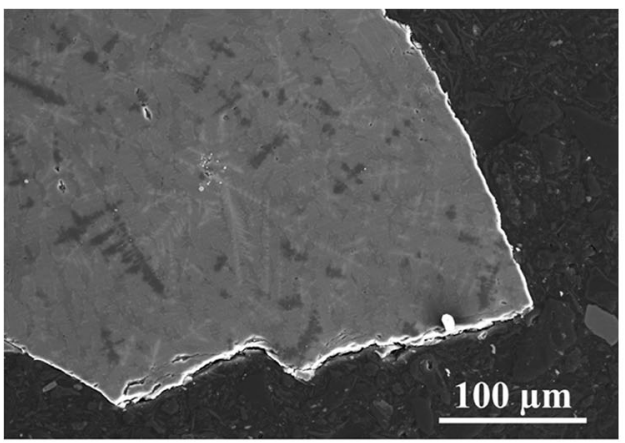

(a) Without oxidation

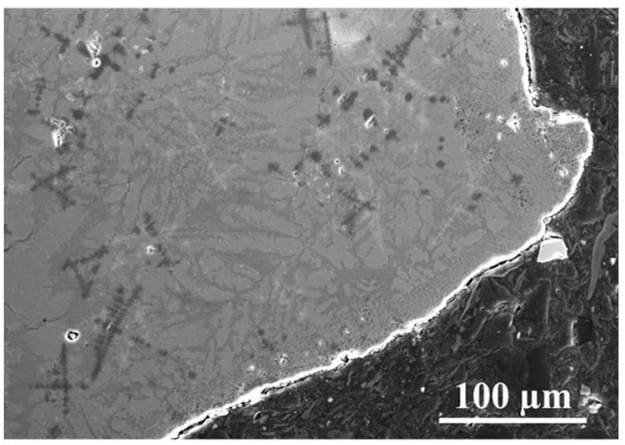

(c) $1473 \mathrm{~K}(\mathrm{~S}-2)$

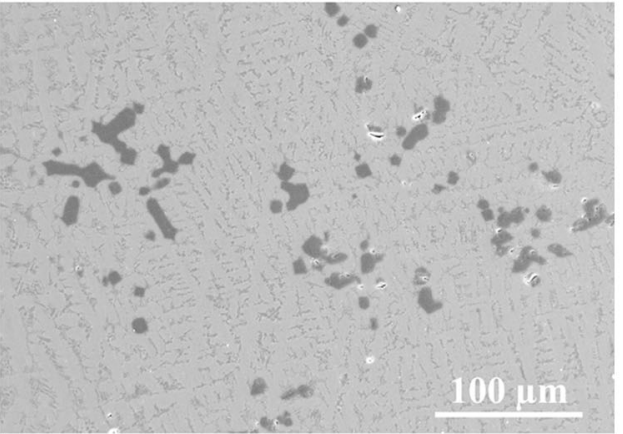

(e) $1673 \mathrm{~K}$ (S-12)

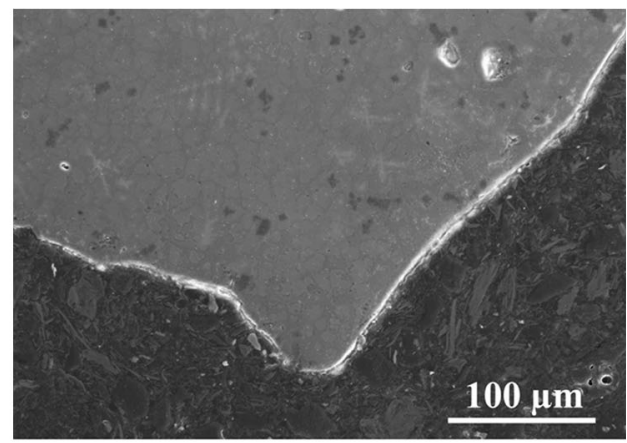

(b) 1373 K (S-1)

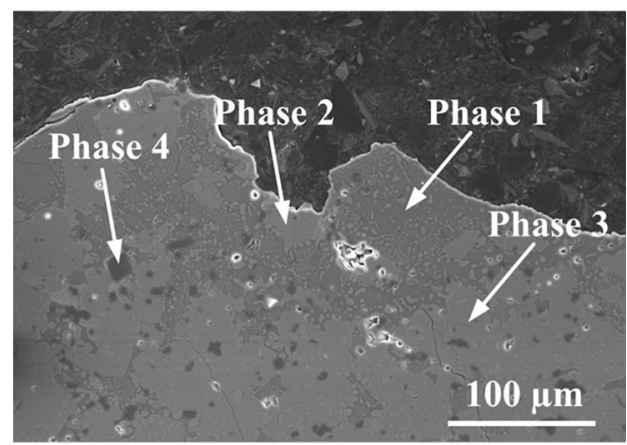

(d) 1573 K (S-5)
Thus, in order for the majority of the sulfur in the slag to be removed by oxidation, sulfur has to diffuse from the bulk of the slag to the particle surface where reaction (2) can take place. It is well known that diffusion in solid state is a very slow process. This also explains why no effect of the temperature can be seen in Fig. 4 between 1373 and $1573 \mathrm{~K}$. It is likely that the reaction time of $60 \mathrm{~min}$ is not sufficient for identifying the effect of temperature. If very long reaction times would be applied, this effect would become apparent. However, this is of little interest since very long treatment times would be highly unpractical from an industrial view point. In fact, the above findings indicate that it is not economically suitable to remove sulfur from ladle slag by oxidation at temperatures below $1573 \mathrm{~K}$.

These results differ considerably compared to what was recently reported by Hiraki et al. [5]. The authors reported a degree of sulfur removal above $90 \%$ after $60 \mathrm{~min}$ of reaction with $\mathrm{Ar}-\mathrm{O}_{2}\left(p_{\mathrm{O}_{2}}\right.$ was $\left.0.21 \mathrm{~atm}\right)$ gas mixture at $1373 \mathrm{~K}$. They also report a considerable effect of temperature, in the temperature range 1173-1373 K. However, there are some significant differences in experimental conditions between the study of Hiraki et al. and the present work. In the present study, approximately, $9.5 \mathrm{~g}$ of slag powder (1-3 $\mathrm{mm}$ or $180-250 \mu \mathrm{m}$ in size) was used in a crucible with an inner diameter of $25 \mathrm{~mm}$. Hiraki et al. used $0.5 \mathrm{~g}$ of slag $(<212 \mu \mathrm{m}$ in size $)$ in a crucible with inner diameter of $27 \mathrm{~mm}$. Additionally, Hiraki et al. used a slag containing considerable less sulfur $(0.19$ mass\%) and large amount of $\mathrm{CaF}_{2}$ (6.58 mass\%) [5]. Both the differences in the nature of the slag and the ratio of mass/surface area could be the factors leading to the great difference in sulfur removal. Although the kinetic conditions in the study of Hiraki et al. favor the desulfurization of the slag, it would be challenging to implement the same ratio of 
Fig. 3 Sulfur mappings of slag a without oxidation, $\mathbf{b}$ oxidation at $1373 \mathrm{~K}$, c oxidation at $1473 \mathrm{~K}$, and $\mathbf{d}$ oxidation at $1573 \mathrm{~K}$

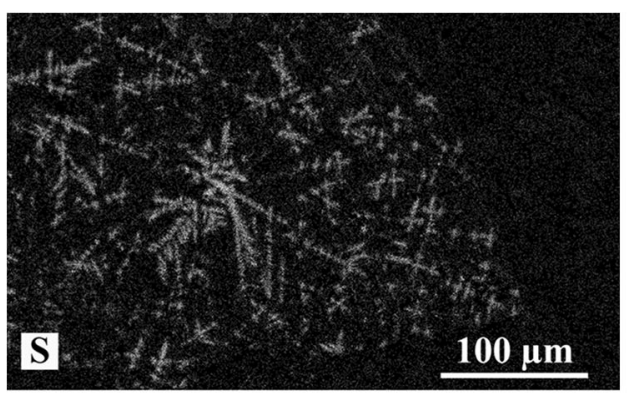

(a) Without oxidation

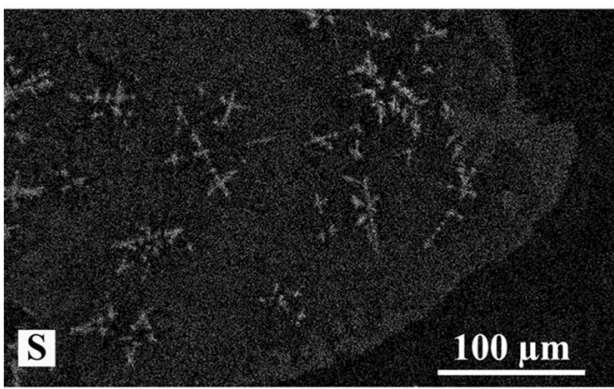

(c) $1473 \mathrm{~K}$ (S-2)

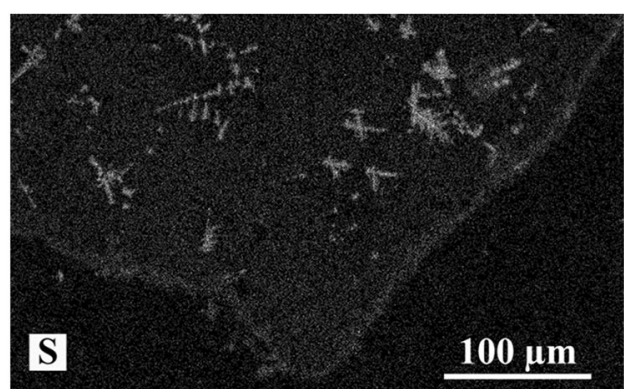

(b) 1373 K (S-1)

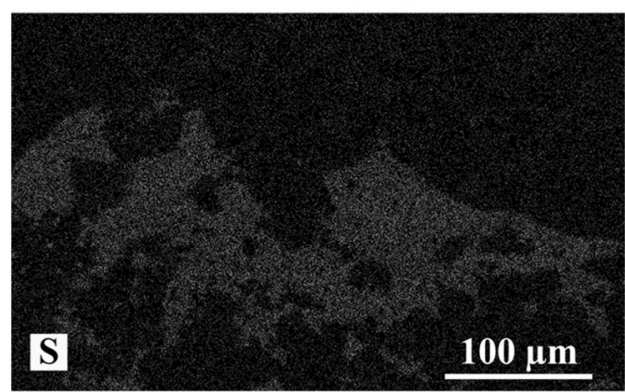

(d) 1573 K (S-5)

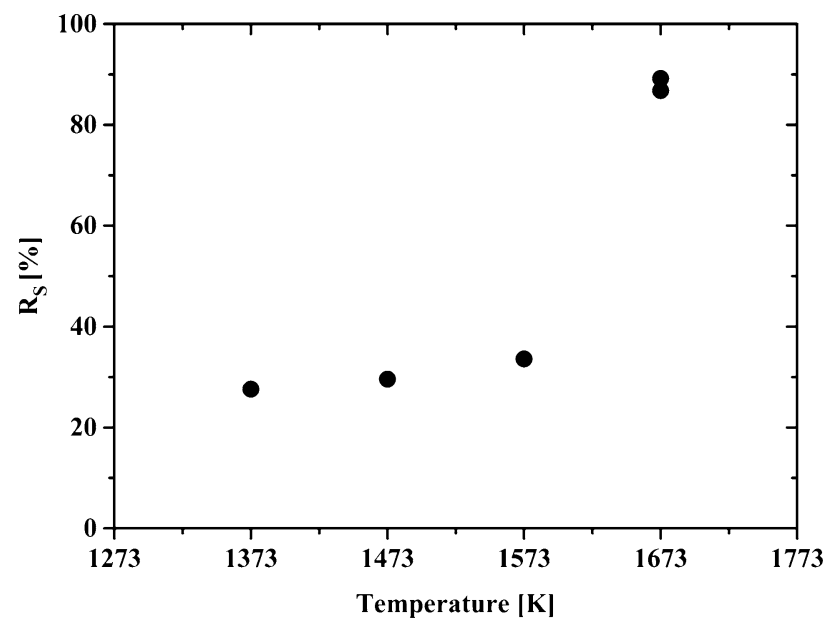

Fig. 4 Degree of sulfur removal as a function of temperature in the range $1373-1673 \mathrm{~K}$, slags contained in $\mathrm{Al}_{2} \mathrm{O}_{3}$ crucible

mass/surface area in industrial application. A very large reaction vessel would be required in order to obtain similar conditions. Additionally, the slag would need to be crushed into a fine powder which would require considerable amounts of energy.

\section{Sulfur removal of liquid slag}

Sulfur can also be removed from liquid slag by oxidation. In this case, sulfide ions, $\mathrm{S}^{2-}$, in the slag react with oxygen and form $\mathrm{SO}_{2}$ gas. The sulfur is then removed to the atmosphere. This reaction is described below:

$\mathrm{S}_{\text {Slag }}^{2-}+\frac{3}{2} \mathrm{O}_{2}(g)=\mathrm{O}_{\text {Slag }}^{2-}+\mathrm{SO}_{2}(g)$

Sulfur also has the possibility to form sulfate ions, $\mathrm{SO}_{4}^{2-}$, in the liquid slag. This can happen if sulfide ions react with oxygen and form sulfate in the slag, which is described in reaction (5):

$\mathrm{S}_{\text {Slag }}^{2-}+2 \mathrm{O}_{2}(g)=\mathrm{SO}_{4 \text { Slag }}^{2-}$

As can be seen, in this case, sulfur remains in the slag as sulfate. When reaction (5) predominates, sulfur cannot be removed by further oxidation.

Table 5 Thermodynamic data used for constructing the $\mathrm{Ca}-\mathrm{S}-\mathrm{O}$ stability diagram in Fig. 5

\begin{tabular}{lllll}
\hline Reaction & $\Delta G^{\mathrm{o}}(\mathrm{J} / \mathrm{mole})$ & Temperature range $(\mathrm{K})$ & Reference \\
\hline $\mathrm{CaS}(s)=\mathrm{Ca}(l)+\frac{1}{2} S_{2}(g)$ & $548,000-103.8 \times T$ & $1112-1757$ & [7] \\
$(\alpha) \mathrm{CaSO}_{4}(s)=\mathrm{CaO}(s)+\mathrm{SO}_{2}(g)+\frac{1}{2} \mathrm{O}_{2}(g)$ & $453,400-231.9 \times T$ & $1468-1638$ & [7] \\
$\mathrm{SO}_{2}(g)=\frac{1}{2} \mathrm{~S}_{2}(g)+\mathrm{O}_{2}(g)$ & $361,700-72.68 \times T$ & $718-2273$ & [7] \\
$\mathrm{CaO}(s)=\mathrm{Ca}(l)+\frac{1}{2} \mathrm{O}_{2}(g)$ & $640,000-108.6 \times T$ & $1112-1757$ & {$[7]$} \\
\hline
\end{tabular}




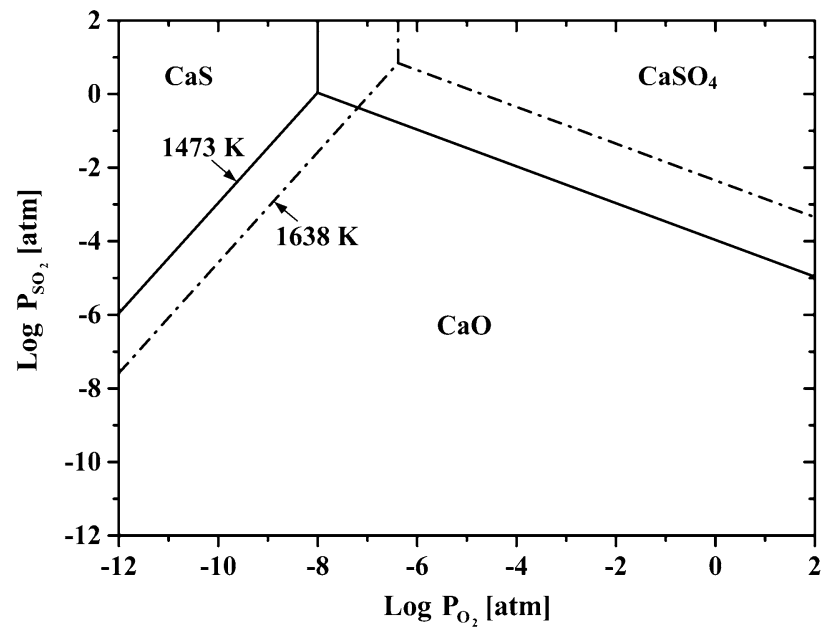

Fig. 5 Stability diagram of the Ca-S-O system at 1473 and $1638 \mathrm{~K}$ based on the data listed in Table 5

Figure 4 shows clearly that a substantial amount of sulfur was removed from the slag at $1673 \mathrm{~K}$. The higher sulfur removal rate at this temperature is governed by the fact that the slag is mostly liquid. When the slag is liquid, the mass transfer of sulfur is greatly increased compared to solid slag. Sulfur will be transferred from the bulk to the surface where reaction (4) can take place. As seen from reactions (4) and (5), the oxygen potential plays an important role. Similar as in the case of solid sample, (see in Fig. 5) a lower oxygen partial pressure than unity might be beneficial for the removal of sulfur from the slag.

The degree of sulfur removal is plotted against the oxygen partial pressure in Fig. 6. No substantial effect of oxygen potential on sulfur removal can be observed, especially at lower oxygen partial pressures. When the oxygen pressure is increased to $1 \mathrm{~atm}$, a slight increase in the degree of sulfur removal is observed. These results are somewhat different than what have been previously reported $[4,8]$. Pelton et al. reported that the sulfur removal rate is increasing with increasing partial pressure of oxygen above $0.3 \mathrm{~atm}$ [4]. This is in agreement with the present study. However, the authors also found that when the oxygen partial pressure is below $0.3 \mathrm{~atm}$, the sulfur removal rate increased with decreasing oxygen partial pressure down to $0.0066 \mathrm{~atm}$. This behavior could not be observed in the present work (Fig. 6). Pelton et al. used blast furnace slags in their study which have considerably higher $\mathrm{SiO}_{2}$ content and lower $\mathrm{Al}_{2} \mathrm{O}_{3}$ content. Additionally, Pelton et al. employed higher gas flow rates than the present study. It is possible that the differences in slag composition and in experimental conditions could lead to the difference in results. Turkdogan and Pearce reported that the desulfurization rate of $\mathrm{CaO}-\mathrm{SiO}_{2}$ melts was noticeably slower in pure oxygen atmosphere compared to pure $\mathrm{CO}_{2}$

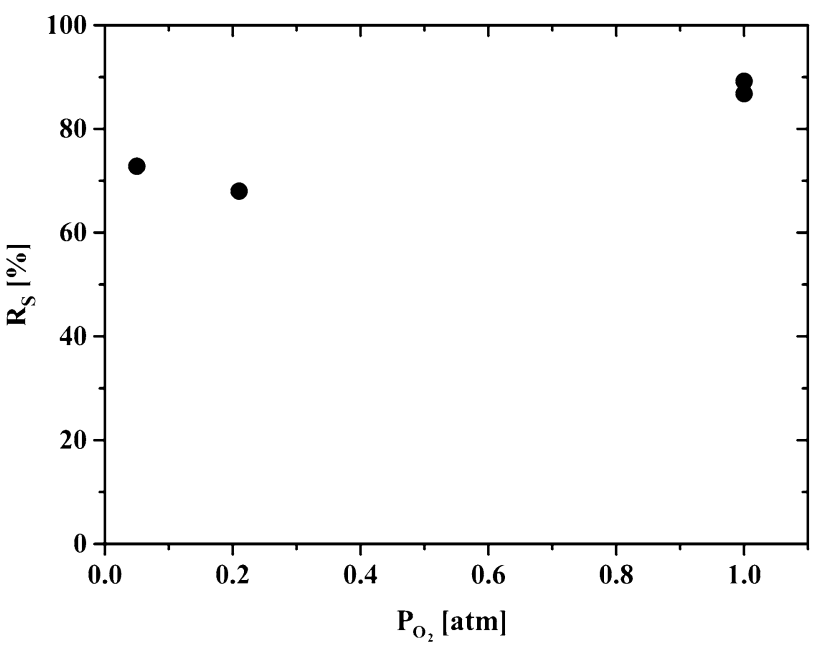

Fig. 6 Degree of sulfur removal against oxygen partial pressure at $1673 \mathrm{~K}$, slags contained in $\mathrm{Al}_{2} \mathrm{O}_{3}$ crucible

or $1 \% \mathrm{O}_{2}+\mathrm{N}_{2}$ gas mixture [8]. These results are in disagreement with the present study. The authors pointed out that they had problems reproducing their experiments in pure oxygen atmosphere. Further studies would be required to investigate in depth the dependence of oxygen at lower pressures. The subsequent experiments were carried out at $1 \mathrm{~atm}$ oxygen partial pressure. The increase of the degree of sulfur removal with increasing oxygen partial pressure strongly suggests that the formation of sulfate in the slag is avoided with the present experimental conditions. Kobayashi et al. concluded that $\mathrm{CaS}$ is oxidized to $\mathrm{CaO}$ above $1223 \mathrm{~K}$ in air [1]. Pelton et al. also concluded that no appreciable amount of sulfate or oxy-sulfide species was formed within the bulk slag at any time [4].

In Fig. 7, the degree of sulfur removal is plotted against the reaction time for slags contained in $\mathrm{Al}_{2} \mathrm{O}_{3}$ and $\mathrm{MgO}$ crucibles. It can be seen that the sulfur removal rate decreases with time, only a small decrease of sulfur concentration is observed between 60 and $120 \mathrm{~min}$ of oxidation. The decrease of the sulfur removal rate could be due to two factors. The first reason could be that the mass transfer of sulfur from the bulk to the liquid surface is slowed down when the concentration of sulfur becomes lower. The second reason could be that the mass transport of $\mathrm{SO}_{2}$ gas away from the liquid surface is too slow. The equilibrium constant for reaction (4) can be expressed as

$K_{(4)}=\frac{a_{\mathrm{O}^{2-}} \times p_{\mathrm{SO}_{2}}}{a_{\mathrm{S}^{2-}} \times p_{\mathrm{O}_{2}}^{3 / 2}}$

The equilibrium constant indicates that in order to keep reaction (4) proceeding to the right-hand side, a lower $\mathrm{SO}_{2}$ pressure is needed when the activity of $\mathrm{S}^{2-}$ becomes lower. This aspect could be elaborated better using the sulfide capacity. A modified version of the sulfur capacity based 


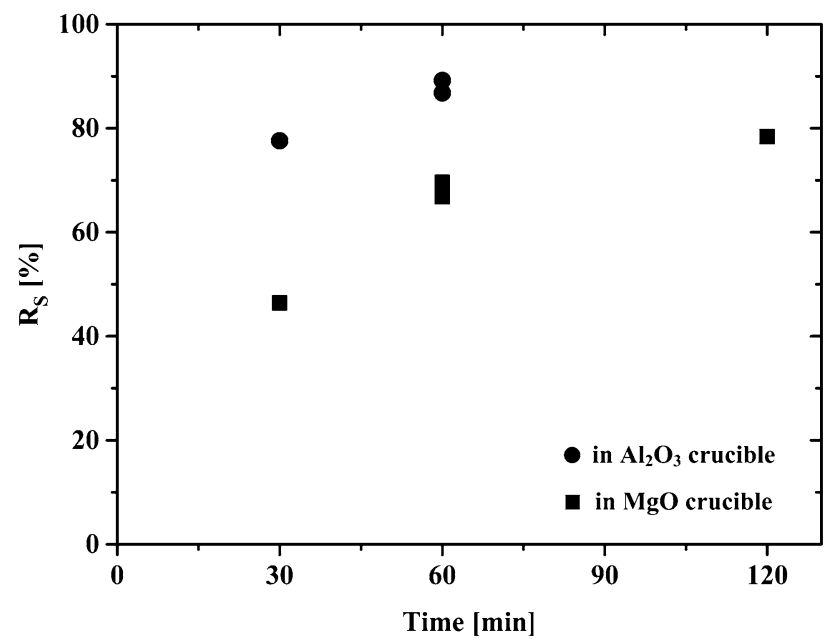

Fig. 7 Degree of sulfur removal against reaction time for slag contained in $\mathrm{Al}_{2} \mathrm{O}_{3}$ and $\mathrm{MgO}$ crucibles at $1673 \mathrm{~K}$

on reaction (4) was used in the subsequent discussion. In the conventional expression of sulfide capacity, the potential of sulfur is expressed as the partial pressure of $S_{2}$ gas. The principle of the sulfide capacity is that it is only depended on the slag composition and temperature. An expression of the sulfur concentration as related to the sulfide capacity and the potentials of oxygen and sulfur is given in Eq. (7):

$(\operatorname{mass} \% S)=C_{S}^{\prime} \times \frac{p_{\mathrm{SO}_{2}}}{p_{\mathrm{O}_{2}}^{3 / 2}}$

From the above expression, it can be seen that, at a constant temperature, the sulfur concentration can be lowered by either increase the oxygen partial pressure or by decreasing the partial pressure of $\mathrm{SO}_{2}$. In the present case, this would require to increase the mass transport of produced $\mathrm{SO}_{2}$ to the main gas stream. This mass transfer depends on (1) the gas flow rate, (2) the surface area of the container, and (3) the distance from the liquid surface to the edge of the crucible. The effect of gas flow rate was investigated, and the results can be seen by comparing $R_{S}$ between sample S-12 and S-13. No appreciable effect could be observed; thus, reason (1) can be ruled out for the present experimental conditions. Unfortunately, the experimental equipment prevented using even higher gas flow rates. Hence, the latter two would be the dominating factors for the rate and final degree of sulfur removal.

Figure 7 indicates that it would require very long reaction times to reduce the sulfur to even lower levels. It is reasonable to expect that the reaction time can be decreased by (1) stirring the melt continuously during the oxidation and (2) optimizing the mass transfer from the liquid surface in the gas phase. The surface area of the slag contained in the $\mathrm{Al}_{2} \mathrm{O}_{3}$ crucibles is approximately $50 \%$ larger compared to the slag in the $\mathrm{MgO}$ crucibles, if any meniscus effects are neglected. It is reasonable to expect that this difference would affect the sulfur removal of the slag, since the possible sites for reaction (4) to take place depend directly on the surface area. To investigate this aspect, a smaller $\mathrm{Al}_{2} \mathrm{O}_{3}$ crucible with the same inner diameter (sample S-11) as the $\mathrm{MgO}$ crucibles was used. In Table 4, it can be seen that the final sulfur content is higher compared to the slags contained in the larger $\mathrm{Al}_{2} \mathrm{O}_{3}$ crucibles (sample S-8 and S-9) and even higher than the slag kept in $\mathrm{MgO}$ crucibles. These experimental results are in accordance with the above discussion about the effect of the shape of the container.

A possible explanation for the difference in results between the crucibles seen in Fig. 7 could be the change in slag composition due to the dissolution of $\mathrm{Al}_{2} \mathrm{O}_{3}$ and $\mathrm{MgO}$, respectively. In Table 4 , it can be seen that a considerable amount of $\mathrm{Al}_{2} \mathrm{O}_{3}$ was dissolved from the crucible wall (sample S-6 through S-11) compared to the initial slag composition in Table 1. The dissolution of $\mathrm{MgO}$ was found to be very limited. The dissolution of $\mathrm{Al}_{2} \mathrm{O}_{3}$ would affect the final sulfur concentration in two ways. Firstly, the dissolution of $\mathrm{Al}_{2} \mathrm{O}_{3}$ into the slag will affect the slag composition. This will also cause dilution of the sulfur concentration. With a simple mass balance, this effect can be evaluated. The extent of the dilution and the effect on the sulfur concentration as well as the $R_{S}$ were calculated for the liquid slags contained in $\mathrm{Al}_{2} \mathrm{O}_{3}$ crucibles. The results of this calculation are summarized in Table 6. It was assumed that the total amount of $\mathrm{CaO}$ was constant throughout the experiment. As can be seen, the dilution of sulfur due to the dissolution of $\mathrm{Al}_{2} \mathrm{O}_{3}$ does not account for the whole difference as observed in Fig. 7. It is also possible that the dissolution of $\mathrm{Al}_{2} \mathrm{O}_{3}$ would affect the slag's ability to release sulfur. This was investigated using additions of $\mathrm{Al}_{2} \mathrm{O}_{3}$ to slag contained in $\mathrm{MgO}$ crucibles, in order to control the final $\mathrm{Al}_{2} \mathrm{O}_{3}$ content. The $R_{S}$ is plotted against the final $\mathrm{Al}_{2} \mathrm{O}_{3}$ content for these slags in Fig. 8. From the figure, it becomes evident that the addition of $\mathrm{Al}_{2} \mathrm{O}_{3}$ decreases the sulfur removal rate. This further supports the reasoning that the sulfur removal is greatly dependent on the surface area.

\section{Industrial Consideration}

The present results show clearly that it is possible to effectively remove sulfur from liquid ladle slag by oxidation. In the present work, almost $90 \%$ of the sulfur was removed after $60 \mathrm{~min}$ of reaction. However, as mentioned in the above discussion, it is likely that higher sulfur removal rates can be achieved by stirring the slag simultaneously while supplying oxygen at a high gas flow rate. It would be interesting to further investigate the sulfur removal by 
Table 6 Calculated final sulfur concentrations and degree of sulfur removal adjusted for dilution of $\mathrm{Al}_{2} \mathrm{O}_{3}$

\begin{tabular}{llllll}
\hline Sample & $\begin{array}{c}\text { Analyzed } S \\
(\text { mass } \%)\end{array}$ & $R_{S}(\%)$ & Dilution $(\%)$ & $S$ (Adjusted) (mass\%) & $R_{S}$ (Adjusted) (\%) \\
\hline S-6 & 0.68 & 73 & 18.1 & 0.80 & 68 \\
S-7 & 0.80 & 68 & 16.8 & 0.93 & 63 \\
S-8 & 0.27 & 89 & 22.6 & 0.33 & 87 \\
S-9 & 0.33 & 87 & 18.6 & 0.39 & 84 \\
S-10 & 0.56 & 78 & 16.8 & 0.65 & 74 \\
S-11 & 0.67 & 73 & 37.7 & 0.92 & 63 \\
S-19 & 1.73 & 31 & 42.4 & 2.46 & 2 \\
\hline
\end{tabular}

the energy benefits would be even greater. However, it should also be pointed out that the sulfur removal includes the emission of sulfuric gases, mainly $\mathrm{SO}_{2}$, which have several negative environmental effects. This aspect needs also to be carefully considered. Necessary measures in order to prevent emissions of such gases should be taken care of.

\section{Summary}

An investigation of the possibility of removing sulfur from used ladle slag by oxidation was made. Experiments were carried out with used ladle slag. The slag composition and sulfur content were determined prior to the experiments. The initial sulfur content of the slag was 2.5 mass\%. Experiments were conducted in the temperature range $1373-1673 \mathrm{~K}$. The slags were analyzed for their final sulfur content and chemical composition after each experiment. Some slags were additionally analyzed with SEM + EDS for investigating the sulfur distribution within the slag.

Sulfur was found to be present in the industrial slag as $\mathrm{CaS}$ evenly distributed in the slag. The sulfur removal in solid slag and two-phase mixture was found to be a slow process involving diffusion in solid state. Due to the slow diffusion, the sulfur removal rate was found to be practically independent of the temperature in the 1373-1573 K range. Sulfur removal of solid slag is thus unsuitable for industrial practice.

When the slag was mostly liquid, at $1673 \mathrm{~K}$, the sulfur removal was increased significantly. After $60 \mathrm{~min}$ of oxidation, more than $85 \%$ of the sulfur could be removed. This indicates that it would be possible to remove sulfur from used slag in industry. The degree of sulfur removal was found to increase with increasing oxygen partial pressure. On the other hand, the increase was quite limited. In fact, air could be used for the sulfur removal in practice. The sulfur removal rate was found to depend directly on the surface area of the slag, increasing with increasing area. This suggests that higher sulfur removal rates could be achieved by stirring the slag in combination with a high gas flow. 
Acknowledgments The authors would like to thank Jan-Erik Andersson and Ovako Hofors, Sweden, for their help and financial support.

\section{References}

1. Kobayashi K, Hiraki T, Nagasaka T (2012) Oxidation of pure solid $\mathrm{CaS}$ with $\mathrm{Ar}-\mathrm{O}_{2}$ gas mixture. High Temp Mater Process 31(4-5):667-673

2. Lynch DC, Elliott JF (1980) Analysis of the oxidation reactions of CaS. Metall Trans B 11B:415-425

3. Agrawal B, Yurek GJ, Elliott JF (1983) Kinetics and mechanism of the desulfurization of liquid blast furnace slags by $\mathrm{Ar}-\mathrm{H}_{2} \mathrm{O}$ gas mixtures. Metall Trans B 14B:221-230
4. Pelton AD, See JB, Elliott JF (1974) Kinetics of evolution of $\mathrm{SO}_{2}$ from hot metallurgical slags. Metall Trans 5:1163-1171

5. Hiraki T, Kobayashi J, Urushibata $S$, Matsubae K, Nagasaka $T$ (2012) Removal of sulfur from $\mathrm{CaF}_{2}$ containing desulfurization slag exhausted from secondary steelmaking process by oxidation. Metall Trans B 43B:703-709

6. Kowalski M, Spencer PJ, Neuschütz (1995) Phase diagrams. In: Slag atlas, 2nd edn. Verlag Stahleisen GmbH, Düsseldorf, pp 21-212

7. Turkdogan ET (1980) Physical chemistry of high temperature technology. Academic press, New York

8. Turkdogan ET, Pearce ML (1963) Kinetics of sulfur reaction in oxide melt-gas systems. Trans Metall Soc AIME 227:940-949 